\title{
Market Segmentation and Dynamic Analysis of Sparkling Wine Purchases in Italy
}

\author{
Francesca Bassi ${ }^{a}$, Fulvia Pennoni ${ }^{b}$ and Luca Rossetto ${ }^{c}{ }_{(\mathbb{D}}$
}

\begin{abstract}
The Italian market of sparkling wines increases as volume and assortment (such as brands, appellations, typologies) mainly because of sparkling Prosecco consumption. We investigate the repeated purchase behavior of sparkling wines in two years within the supermarket channel through scanner data collected from a consumer panel. We propose a Hidden Markov Model to analyze these data, assuming an unobservable process to capture consumers' preferences and allowing us to consider purchases sparsity over time. We consider multivariate responses defining types of purchases, namely price, appellation, and sugar content. Customers' covariates influence the initial and transition probabilities of the latent process. We identify five market segments, and we track their evolution over time. One segment includes Prosecco-oriented consumers, and we show that loyalty to Prosecco changes strongly over time according to the region of residence, income, and family type. The findings improve the understanding of the market and may provide evidence to design successful marketing strategies. (JEL Classifications: C33, C51, D12, L66)
\end{abstract}

Keywords: dynamic market segmentation, hidden Markov model, loyalty, repeated purchases, variety-seeking behavior.

\section{Introduction}

In the last decade, the vigorous growth in the sparkling wine market has been coupled by substantial increase growth in brands, appellations, price range, as well as other attributes (e.g., packaging) to catch consumers' attention. While the international market is dominated mainly by three appellations-Champagne, Cava,

The authors kindly thank the editor and the reviewers for their useful comments and suggestions.

a Department of Statistical Sciences, University of Padova, Italy, via C. Battisti 241, 35121 Padova, Italy; e-mail: francesca.bassi@unipd.it.

${ }^{\mathrm{b}}$ Department of Statistics and Quantitative Methods, University of Milano-Bicocca, Italy, via Bicocca degli Arcimboldi 8, 20126, Milano, Italy; e-mail: fulvia.pennoni@unimib.it.

${ }^{c}$ Department of Land, Environment, Agriculture and Forestry, Forestry (Tesaf), University of Padova, via Università 16, 35020 Legnaro (Padova), Italy; e-mail: luca.rossetto@unipd.it (corresponding author).

(C) The Author(s), 2021. Published by Cambridge University Press on behalf of American Association of Wine Economists. This is an Open Access article, distributed under the terms of the Creative Commons Attribution licence (http://creativecommons.org/licenses/by/4.0/), which permits unrestricted re-use, distribution, and reproduction in any medium, provided the original work is properly cited. 
Prosecco - in the Italian market, there is a greater fragmentation due to the preponderance of numerous domestic products having a complex geographical classification system (Corriere Vinicolo, 2019).

The sparkling wine market is highly competitive, while the marketing strategies adopted by sellers may easily endanger the brand loyalty of fast-moving consumers, as reported in other studies (Meixner and Knoll, 2012; Rossetto and Gastaldello, 2018).

The reference literature on sparkling wines is mainly focused on technical and sensorial aspects (Culbert et al., 2017), consumers' behavior (Charters et al., 2011; Verdonk et al., 2017), and wine purchases. Some recent contributions deal with spatial differences in wine and alcohol markets (Hart and Alston, 2020), while less attention is devoted to studying changes in purchase behavior over time.

We propose to fill this gap by considering the market dynamics of repeated purchases and the socio-demographic factors that may favor them. The results may help design effective marketing strategies. We aim to evaluate sparkling wine purchases by investigating the customer choices over time. Using information collected from a panel of Italian families who purchase in retail stores, collected repeatedly for several months, we draw customers' profiles and analyze if and how their purchasing behavior changes within a two-year time horizon. Moreover, we evaluate how consumers and their family features affect the probability to belong to a certain category or profile at the initial period and retaining or changing this category over time. To analyze these data, we propose a multivariate statistical model, namely a Hidden Markov Model (HMM) (Bartolucci, Farcomeni, and Pennoni, 2013). The HMM is employed in marketing applications since it allows us to identify hidden types of prospects in the acquisition process and connect the dynamics across different customer profiles. As far as we know, the HMM was applied in the field of wine economics for the first time by Bassi, Pennoni, and Rossetto (2020). In this article, we use an HMM for multivariate categorical responses with a longitudinal structure, accounting for the sparsity of the purchases while considering an unbalanced panel and testing covariates' effects. Compared to the currently existing models in the literature, the HMM does not require strong parametric assumptions, and it is robust for model misspecification.

The rest of the article is structured as follows. In Section II, we review the literature on the customer behavior of repeated purchases. In Section III, we illustrate the Italian sparkling wine market, available data, and the statistical methodology. In Section IV, we show the results of the proposed HMM, and in Section V, we discuss the results with reference to the existing literature, and finally, we report some conclusions.

\section{Literature Review}

Wine consumption involves repeated purchases, as it usually happens with routine food products and beverages. The dynamics of purchases have been investigated 
as an exploratory behavior (Meixner and Knoll, 2012), which explains why consumers buy the same brand or product or change them (variety) in repeated purchases (Barharrell and Denison, 1995). Accordingly, a consumer's state of dependence occurs when purchases depend on past consumption history (Thomadsen and Seetharaman, 2018). A positive state of dependence is detected as habits (automatic purchase process), inertial purchases (high probability of making the same purchase), loyalty (repurchase of the same brand), or as a positive effect of the last purchase on the current one. Conversely, a negative state of dependence reduces the probability of repurchasing the same product on the next occasion. This approach is named variety-seeking behavior (VSB).

The positive or negative state of dependence is usually linked to specific attributes, such as brand, flavor, size, and quality, rather than the product itself, while heterogeneity is found among consumers' state of dependence (Thomadsen and Seetharaman, 2018). Studies on food products such as ketchup and yogurt (Adamowicz and Swait, 2012) detected habit and variety-seeking segments.

The reasons behind the state of dependence have been largely investigated in the wine market as loyalty and VSB. Loyalty (Rungie et al., 2006) reflects how strong the brand identity is in the mind of consumers who have acquired experience and formed their own habits.

Conversely, the VSB is historically linked to the optimal stimulation level, the arousal theory (McAlister, 1982; Venkatesan, 1973), and the concept of satiation. McAlister (1982) proposed a dynamic model for the attribute satiation, where the consumption history creates an attribute inventory that is depleted (the customer forgets the attribute) or replaced (repeated consumption) over time. More recently, Sevilla, Lu, and Kahn (2019) built an extended model explaining that strategies mitigating the satiation depend on consumption features (quantity consumed, time, and frequency of consumption) and perception features such as categorization, attention, memory, and cognition.

A different approach is proposed in Yoon and Kim (2018). Their study shows that consumers living in a constrained socio-economic status perceive their life as unsatisfactory. Accordingly, these consumers are inclined to compensate for this life status by choosing among a wide assortment of products, that is, they behave as varietyseeking purchasers (Yoon and Kim, 2018).

The conspicuous VSB literature allows us to draw a general profile of the varietyseeking customer revolving around the concept of sensation seeking. Generally speaking, VSB consumers prefer products connected to novelty and stimulation (Raju, 1980), such as choosing new brands, avoiding routine behaviors while acting differently from time to time. In this framework, high-sensation seeker consumers tend to make impulsive choices and be more attentive to information. Inman (2001) suggests that consumers may change flavors more frequently than brands. The effect of satiation is observed especially in the food domain (Baltas, 
Kokkinaki, and Loukopoulou, 2017), where VSB is stimulated in products exhibiting hedonic attributes (Van Trijp, Hoyer, and Inman, 1996). Sensation seeking can be interpreted as a compensatory behavior in economically stuck consumers reacting to their unsatisfactory life conditions (Yoon and Kim, 2018).

When looking at extreme variety-seekers, referred to as switchers (Knox and Walker, 2001), brand commitment lowers, and the desire to switch brands may be easily triggered by factors such as promotional prices or fancier packaging (Olsen et al., 2015). On the other hand, it is important to consider context-related factors such as the wide product assortment offered in supermarkets, which can encourage switching behaviors (Diehl and Poynor, 2010), or price discounting campaigns that attract customers and lock them in for their subsequent purchases (Thomadsen and Seetharaman, 2018).

In the wine domain, Olsen et al. (2015) reported a literature review where VSB in wine is modeled using consumer features, product involvement, and wine knowledge. For instance, differences in VSB were found among age, income, and education level (Dodd, Pinkleton, and Gustafson, 1996) or different risk-taking segments with older consumers likely to choose new wines (Mueller, Remaud, and Chabin, 2011). Personality traits can also affect wine and beer purchases (Gustavsen and Rickertsen, 2019). VSB is often detected in innovators, early adopters, and riskadverse consumers (Campbell and Goodstein, 2001). Personal involvement is higher in variety-seeking consumers since they are more aware of grape varietals (Madureira and Simoes de Sousa Nunes, 2013) or environmental aspects. Therefore, they switch the regions of their wine purchases (Dodd, Pinkleton, and Gustafson, 1996), or they choose among sustainable wines (Kelley et al., 2017). The VSB may arise from an imperfect knowledge of wine consumers. Shoppers are often confused when selecting wines and can barely remember their last wine purchase (Hussain, Cholette, and Castaldi, 2007). Following Dodd, Pinkleton, and Gustafson (1996), wine experts show a high VSB because of their better information level; conversely, Viot (2012) reports that subjective knowledge does not influence the number of wines chosen.

More recently, the VSB has been detected in consumers who prefer to taste different wines and therefore move across market segments because they know one or more wine attributes such as grape variety, origin, brand (Ellis and Caruana, 2018) or, conversely, because they are not well informed about wines (Ellis and Thompson, 2018). Moreover, a vast wine assortment encourages consumers to look for variety while eroding their loyalty to brands, especially in products such a wine having a strong hedonic component (Inman, 2001; Ellis and Thompson, 2018).

So far, the literature on VSB for wine has not paid attention to wine types. Specifically, the consumption of sparkling wines is affected by motivations that differ with respect to still wines. Charters et al. (2011) thoroughly analyzed Champagne consumption, which carries symbolic motivations as these wines are often consumed on special occasions like celebrations, holidays, and in specific 
moments of the day, depending on the cultural context. Bubbles represent the distinctive trait of these wines, and they are often associated with positive emotions and dynamism. Conversely, the peculiarities of Champagne make its consumption differ with respect to "regular" sparkling wines that constitute a separate product category (Thach and Olsen, 2006).

The Italian literature on sparkling wines has increased recently due to an increase in the production of sparkling wines. Thiene et al. (2013) pointed out consumer patterns and different willingness to pay (WTP) for Prosecco appellations by segmenting the wine market into groups using a latent class regression model on survey data. Onofri, Boatto, and Dal Bianco (2015) detected a segmentation among consumers showing different preferences for the two Prosecco denominations. Experimental research done by Vecchio et al. (2018) showed how consumers perceived the sparkling production process and brand differently (Charmat vs. Champenoise). Rossetto and Gastaldello (2018) evaluated the different loyalty and VSB when purchasing sparkling wines in supermarkets. Using a model based on a Dirichlet distribution, they detected high loyalty toward Prosecco appellations and moderate VSB.

In the following, we analyze the dynamics of purchases of sparkling wines by using a different approach. We apply a multivariate HMM (Bartolucci, Farcomeni, and Pennoni, 2013) to identify consumer types according to the dynamic patterns and detect possible effects of the customers' socio-demographic characteristics. The proposed model accounts for a sequence of purchased brands and enables us to evaluate consumer loyalty while segmenting the purchase base, and it gives stores a method to manage long-term buying through suitable marketing strategies.

\section{Data and Methods}

\section{A. Italian Sparkling Wine Sales}

An outline of the Italian sparkling wine market is preparatory to the analysis of repeated purchases done in this article. In 2018, Italian sparkling wine production was approximately 6.7 million hectoliters, of which 70\% were exported (Corriere Vinicolo, 2019). Sparkling wine production is dominated by Prosecco (approximately $75 \%$ of total production), which accounts for three appellations (a Controlled Denomination of Origin Prosecco and two Guaranteed Controlled Denominations of Origin Conegliano-Valdobbiadene Prosecco and Asolo Prosecco). The Italian consumption of sparkling wines is covered by Prosecco and a wide variety of brands that differ in the method of production (Charmat and Classic), appellation, grape variety, and price. Charmat sparkling wines (approximately $94 \%$ of production) account for the main appellations such as Prosecco, Asti, and Brachetto, while the classic method includes small appellations, such as Franciacorta, Trento, Oltrepo Pavese, and Alta Langa (Corriere Vinicolo, 2019). Concerning the sugar content (from brut to sweet wines), brut wines include appellations produced through the classic method (Franciacorta, Trento, etc.) and the 
Charmat method (Prosecco), while sweet wines are found in two leading appellations: Asti (white wine) and Brachetto (red wine). Moreover, there is a significant production of Charmat sparkling wines with no appellation, covering a wide range of sugar contents (brut and sweet).

Looking at the domestic sales in supermarkets, sparkling wines without appellation and Prosecco represent approximately 30\% (Rossetto and Gastaldello, 2018). Classic-method wines (Franciacorta, Trento, and Oltrepo Pavese) have a significant market share (22-23\%) and high price positioning. Sweet sparkling wines, such as Asti and Brachetto, and small appellations have market shares of less than $10 \%$. Champagne also has a non-negligible market share in the Italian market (Corriere Vinicolo, 2019). The consumption of sparkling wines is seasonal and strongly affected by holidays such as Christmas, New Year, Easter (especially sweet sparkling wines), or special occasions such as celebrations (birthday, anniversary, etc.) (Charters et al., 2011; Rossetto and Gastaldello, 2018).

\section{B. Data}

Data are provided by an international agency (Nielsen, 2017) from a panel of 9,000 Italian households who recorded their purchases through a scan method over the years 2015-2016. This sample represents the Italian population regarding the area of residence, family size, income, age of the purchaser, and family life stage. The survey collected purchases every month; households may therefore perform multiple purchases in a two-year time horizon. We have a total of 22,362 purchases of sparkling wines made in non-specialized grocery stores (hypermarkets, supermarkets, minimarkets, and discounts) at our disposal. The data refer to the portion of the entire panel of 5,155 households that made at least one purchase in the reference period. Data contain detailed information on purchases: time and place of purchase, intrinsic and extrinsic wine attributes, such as the appellation, label, brand, producer location, and price (Bassi, Pennoni, and Rossetto, 2020).

Families make from 1 to 230 purchases in the reference period: $34.0 \%$ of households bought sparkling wine only once, $19.8 \%$ twice, $11.1 \%$ three times, only a small portion of the sample, $10 \%$, made more than 10 purchases in the two years. Table 1 shows that the average expense per purchase in the whole period was approximately seven euros. The observed quantiles of price show five ordered levels of the categorical response.

The second response variable, namely the type of wine, exhibits that $33.5 \%$ of the observed purchases are of sweet wines and $35.3 \%$ of brut sparkling wines, while extra dry purchases are $19.2 \%$. The share of no appellation sparkling wine purchases is $44.5 \%$, while the Prosecco appellations represent $30 \%$ of the sampled purchases. High-price classic method appellations (Franciacorta, Trento, Oltrepo) represent $12 \%$ of the observed purchases.

Regarding the sample socio-economic characteristics, we used the categorical variables defined within Nielsen's methodology (Nielsen, 2017) and reported in Table 2, 
Table 1

Descriptive Statistics of the Response Variables

\begin{tabular}{lc}
\hline Response Variable & Percentage \\
\hline Euro per purchase (mean 7.06; SE 8.15) & \\
{$[0.78,2.98]$} & 20.0 \\
$(2.98,3.99]$ & 21.0 \\
$(3.99,5.69]$ & 19.0 \\
$(5.56,8.99]$ & 20.0 \\
$(8.99,250]$ & 20.0 \\
Type of wine (sugar content) & \\
Brut & 35.3 \\
Extra dry & 19.3 \\
Dry & 11.9 \\
Sweet & 33.5 \\
Appellation (refermentation method) & \\
No appellation (mostly Charmat) & 44.5 \\
Prosecco DOCG (Charmat) & 12.2 \\
Prosecco DOC (Charmat) & 17.9 \\
Franciacorta DOCG (Classic) & 5.8 \\
Asti DOCG (Charmat) & 5.1 \\
Trento DOC (Classic) & 4.3 \\
Brachetto d'Acqui DOCG (Charmat) & 3.1 \\
Oltrepo Pavese DOCG & 2.0 \\
Dolomiti DOC (Charmat) & 2.2 \\
French appellations (Champagne) & 1.6 \\
Other & 1.3 \\
\hline
\end{tabular}

along with some descriptive statistics. They include the Italian region of residence, the purchaser's age, the family income categorized as very low, below the average, above the average, and high according to the concentration curve of the per capita income, the number of family components, and the family life stages (defined according to the parents and children ages, see the footnote of Table 2). We observe homogeneous purchase distributions among all Italian regions; only Lombardy exhibits more purchases than elsewhere.

\section{Methods}

We employed the multivariate categorical response variables jointly to provide a dynamic overview of the purchase process over time. Homogeneous clusters of consumers are discovered according to the socio-economic features of the households. Specifically, we estimate a multivariate HMM (Bartolucci, Farcomeni, and Pennoni, 2013, 2014) with covariates influencing the latent model to investigate their effects on the purchase dynamics according to the responses shown in Table 2. The model provides the estimated probabilities of consumers being allocated in each segment at the beginning of the period (initial probabilities) and their movements across market segments over time (transition probabilities). It also allows us to disentangle the effects of socio-economic variables on these probabilities. The main 
Table 2

Descriptive Statistics of the Covariates

\begin{tabular}{|c|c|}
\hline Covariate & Percentage \\
\hline \multicolumn{2}{|l|}{ Family members } \\
\hline 1 & 11.9 \\
\hline 2 & 36.4 \\
\hline 3 & 24.6 \\
\hline 4 & 20.2 \\
\hline $5+$ & 6.8 \\
\hline \multicolumn{2}{|l|}{ Region } \\
\hline Piedmont and Aosta Valley & 7.6 \\
\hline Liguria & 2.7 \\
\hline Trentino-South Tyrol and Friuli-Venezia Giulia & 3.3 \\
\hline Veneto & 9.8 \\
\hline Tuscany & 8.5 \\
\hline Umbria and Marche & 4.1 \\
\hline Abruzzo and Molise & 2.0 \\
\hline Campania & 5.5 \\
\hline Apulia & 4.9 \\
\hline Calabria and Basilicata & 3.3 \\
\hline Sicily & 5.9 \\
\hline Lombardy & 23.5 \\
\hline Emilia-Romagna & 8.5 \\
\hline Lazio & 8.3 \\
\hline Sardinia & 2.0 \\
\hline \multicolumn{2}{|l|}{ Purchaser age } \\
\hline $20-34$ & 4.5 \\
\hline $35-44$ & 16.8 \\
\hline $45-54$ & 27.2 \\
\hline $55-64$ & 24.1 \\
\hline$\geq 65$ & 27.4 \\
\hline \multicolumn{2}{|l|}{ Family life stage } \\
\hline Pre & 2.6 \\
\hline New & 6.0 \\
\hline Established & 10.0 \\
\hline Maturing & 11.4 \\
\hline Post & 21.4 \\
\hline Older couples & 41.6 \\
\hline Older singles & 6.9 \\
\hline \multicolumn{2}{|l|}{ Income classes } \\
\hline Very low & 15.2 \\
\hline Low & 27.3 \\
\hline Medium & 37.1 \\
\hline High & 20.4 \\
\hline
\end{tabular}

Notes: Families are classified in life stages (age and children) as follows: "pre family" are singles or couples with no children, and the purchaser is younger than 35; "new" are families with children younger than 6; "maturing" are families that have children under 17 but not all of them are very young nor are any of them between 11 and 17; "established" are families with children between 11 and 17; "post" are families that are singles or couples (35-54) and do not have children under 18; "older couples" are purchasers that are over 55 and have no children under 18; finally, "older singles" who are 55 and older. 
assumption is that the latent process fully explains the observed consumer behavior, and the time-fixed and time-varying customer socio-demographic characteristics describe the dynamics of the underlying latent preferences.

The model is an extension of the latent class model employed with cross-sectional data (Clogg and Goodman, 1984; Pennoni, 2014). Recent inferential and computational developments of the HMM improved the model performance in analyzing time series and panel data in many fields of application (see Bartolucci, Farcomeni, and Pennoni (2013, ch. 3) for a literature review and some illustrative examples).

In the following, we consider the multivariate HMM based on a first-order Markov chain with homogeneous transition probabilities and covariates affecting the latent process while accounting for the unbalanced panel. The response variable is denoted as $Y_{i j t}$, that is, the customer's response $i, i=1, \ldots, n$, for the variable $j$, $j=1, \ldots, r$ having $c_{j}$ categories measured at time $t, t=1, \ldots, T_{i}$. It is worth noting that the number of purchases is customer-specific. The response vector is denoted as $\boldsymbol{Y}_{i t}=\left(Y_{i 1 t}, \ldots, Y_{i r t}\right)$, and we assume that the distribution of the responses depends on a discrete latent variable assumed with a finite number of states ranging from $1, \ldots, k$, and denoted as $\boldsymbol{U}_{i}=\left(U_{i 1}, \ldots, U_{i T}\right)$. The components identified by this latent variable correspond to subpopulations of customers showing different purchasing behavior. We assume that the three responses on the same occasion, $\boldsymbol{Y}_{i t}$, are conditionally independent, given the latent process $U_{i t}$, and the vectors of responses $\boldsymbol{Y}_{i 1}, \ldots, \boldsymbol{Y}_{i T}$ are conditionally independent, given the latent process $\boldsymbol{U}_{i}$. The conditional distribution of each response variable is denoted as

$$
P\left(Y_{i j t}=y \mid U_{i t}=u\right)=\phi_{j y \mid u} .
$$

We account for the influence of socio-demographic features on the latent process by assuming that these affect customers' latent preferences. Let $\boldsymbol{x}_{i t}$ denote the vector of individual covariates available at the $t$ time occasion for customer $i$. Each covariate contributes to the initial customer's allocation at the first purchase occasion across segments and to customers' switch among segments after the first purchase. For this purpose, we model the initial and the transition probabilities as customerspecific through suitable multinomial logit models. Regarding the initial probabilities, we assume the following base-line category logit model:

$$
\log \frac{p\left(U_{i t}=u\right)}{p\left(U_{i t}=1\right)}=\beta_{0 u}+\boldsymbol{x}^{\prime} \boldsymbol{\beta}_{1 u}, \quad u \geq 2,
$$

where $\beta_{0 u}$ is an intercept specific for the latent state and $\boldsymbol{\beta}^{\prime}{ }_{1 \boldsymbol{u}}$ is a column vector of parameters measuring the effect of the covariates.

The transition probabilities of the HMM are modeled as

$$
\log \frac{p\left(U_{i t}=u \mid U_{i t}=\bar{u}\right)}{p\left(U_{i t}=1 \mid U_{i t-1}=\bar{u}\right)}=\gamma_{0 \bar{u} u}+\boldsymbol{x}^{\prime} \gamma_{1 \bar{u} u} t \geq 2, \quad \bar{u} \neq u
$$


where $\gamma_{0 \bar{u} u}$ is the intercept and $\gamma_{1 \bar{u} u}$ is the vector of parameters representing the effects of the covariates on the transition probability from state $\bar{u}$ to state $u$.

Given a sample of independent customers, the log-likelihood of the model has been maximized through the Expectation-Maximization (EM) algorithm (Dempster, Laird, and Rubin, 1977). The EM algorithm requires that the parameters be properly initialized, and additional details on how this is performed as well as on the steps of this algorithm can be found in Chapter 5 of Bartolucci, Farcomeni, and Pennoni (2013). The appropriate number of states that identify the customer segments is selected by using the Bayesian Information Criterion (BIC), which is a measure of the relative goodness of fit accounting for the sample size. Bacci, Pandolfi, and Pennoni (2014) compared the performance of different information criteria, and they showed that most criteria perform reasonably well in choosing the number of appropriate latent states; however, the BIC is preferred for its parsimony. Standard errors of the parameters are used as a measure of accuracy, especially for the covariate's effects. They are obtained as the squared root of the elements on the main diagonal of the inverse observed or expected information matrix computed at the maximum likelihood estimate (Bartolucci, Farcomeni, and Pennoni, 2013). Suitable functions adapted from the R package LMest (Bartolucci, Pandolfi, and Pennoni, 2017) have been used for estimating the proposed HMMs.

\section{Results}

The categorical response variables are rearranged in ordered categories: 5 for the purchase price, 4 for the type of wine, and 11 for appellations (see Table 1). The multivariate HMM is estimated for a number of latent states ranging from 2 to 6 . The results of the model selection procedure (Table 3 ) show a minimum value of BIC corresponding to an HMM with 5 latent states denoted as segments in the following.

\section{A. Customers' Profiles}

The results under the selected HMM are reported in Tables 4 and 5. The consumers' segments estimated according to conditional probabilities as in Equation (1) showed in Table 4, are labeled as: (1) Ordinary Sweet, (2) Ordinary Brut, (3) Sophisticated, (4) Prosecco, and (5) Luxury. The five segments are ordered for average purchase expense. At the initial period, the highest share of customers $(34 \%)$ is allocated to segment (1), defined as Ordinary Sweet. This segment includes low-profile buyers since their purchases are, on average, less than four euros. Ordinary Sweet customers buy mostly sweet sparkling wines with no appellation for special occasions such as holidays or celebrations. Segment (2) represents $19 \%$ of the customers: they spend no more than four euros for a standard (ordinary) brut sparkling wine, with no appellation. This segment is named as that of Ordinary Brut customers and includes low-price purchases, although the average purchase expense is a bit higher than the 
Table 3

Measures of Fit for an Increasing Number of Hidden States

\begin{tabular}{lcc}
\hline Number of Hidden States & BIC & Number of Parameters \\
\hline 2 & 188,713 & 110 \\
3 & 178,429 & 270 \\
4 & 173,349 & 494 \\
5 & 171,955 & 782 \\
6 & 172,384 & 1,134 \\
\hline
\end{tabular}

Table 4

Estimated Conditional Probabilities and Latent Customer Profiles

\begin{tabular}{lccccc}
\hline $\begin{array}{l}\text { Segments (Initial } \\
\text { Weight of Segment) }\end{array}$ & $\begin{array}{c}(1) \\
\text { Ordinary Sweet } \\
(0.34)\end{array}$ & $\begin{array}{c}(2) \\
\text { Ordinary Brut } \\
(0.19)\end{array}$ & $\begin{array}{c}(3) \\
\text { Sophisticated } \\
(0.13)\end{array}$ & $\begin{array}{c}(4) \\
\text { Prosecco } \\
(0.20)\end{array}$ & $\begin{array}{c}\text { Luxury } \\
(0.14)\end{array}$ \\
\hline Responses & \multicolumn{5}{c}{ Estimated conditional probabilities } \\
\hline Average purchase in euros & 0.51 & 0.22 & 0.05 & 0.03 & 0.00 \\
{$[0.78,2.98]$} & 0.21 & 0.30 & 0.24 & 0.19 & 0.00 \\
$(2.98,3.99]$ & 0.13 & 0.19 & 0.39 & 0.26 & 0.01 \\
$(3.99,5.69]$ & 0.10 & 0.18 & 0.27 & 0.28 & 0.22 \\
$(5.56,8.99]$ & 0.05 & 0.11 & 0.14 & 0.24 & 0.76 \\
(8.99, 250] & & & & & \\
Type of wine (sugar content) & 0.07 & 0.78 & 0.00 & 0.07 & 0.97 \\
Brut & 0.02 & 0.14 & 0.02 & 0.59 & 0.00 \\
Extra dry & 0.04 & 0.08 & 0.00 & 0.34 & 0.00 \\
Dry & 0.88 & 0.01 & 0.98 & 0.00 & 0.00 \\
Sweet & & & & & \\
Appellation & 0.95 & 0.69 & 0.01 & 0.01 & 0.01 \\
No appellation & 0.01 & 0.06 & 0.00 & 0.41 & 0.00 \\
Prosecco DOCG & 0.00 & 0.11 & 0.00 & 0.58 & 0.01 \\
Prosecco DOC & 0.00 & 0.00 & 0.16 & 0.00 & 0.40 \\
Franciacorta DOCG & 0.03 & 0.01 & 0.39 & 0.00 & 0.00 \\
Asti DOCG & 0.00 & 0.00 & 0.00 & 0.00 & 0.42 \\
Trento DOC & 0.00 & 0.00 & 0.28 & 0.00 & 0.00 \\
Brachetto d'Acqui DOCG & 0.00 & 0.04 & 0.06 & 0.00 & 0.00 \\
Oltrepo DOCG & 0.00 & 0.00 & 0.00 & 0.00 & 0.14 \\
French appellations & 0.00 & 0.00 & 0.07 & 0.00 & 0.00 \\
Other & & & & &
\end{tabular}

one made by the Ordinary Sweet customers. Thus, the main difference between customers' profiles in segments (1) and (2) is the wine sugar content (sweet vs. brut). Segment (3) represents $13 \%$ of the customers spending more than three euros to buy a Charmat sweet wine such as Asti or Brachetto d'Aqui appellations or more than six euros for some classic method wines such as Franciacorta or Oltrepo. This segment's profile is defined as that of Sophisticated purchases. Segment (4) represents $20 \%$ of customers and is the profile of those loving Prosecco wine having a 
Table 5

Estimates of the Statistically Significant Logit Regression Parameters on the Initial Probabilities of the HMM

\begin{tabular}{|c|c|c|c|c|}
\hline Segments & $\begin{array}{c}\text { (2) } \\
\text { Ordinary Brut }\end{array}$ & $\begin{array}{c}\text { (3) } \\
\text { Sophisticated }\end{array}$ & $\begin{array}{c}(4) \\
\text { Prosecco }\end{array}$ & $\begin{array}{l}\text { (5) } \\
\text { Luxury }\end{array}$ \\
\hline Intercept & - & $-0.82(0.41)$ & - & - \\
\hline \multicolumn{5}{|l|}{ Region } \\
\hline $\begin{array}{l}\text { Trentino-South Tyrol and Friuli } \\
\text { Venezia Giulia }\end{array}$ & - & - & $0.79(0.39)$ & \\
\hline Veneto & - & - & $1.04(0.35)$ & - \\
\hline Campania & $1.85(0.41)$ & $1.18(0.42)$ & - & $1.32(0.44)$ \\
\hline Apulia & $1.14(0.36)$ & $0.71(0.38)$ & - & - \\
\hline Calabria and Basilicata & $1.50(0.40)$ & - & - & - \\
\hline Sicily & $1.24(0.34)$ & - & - & - \\
\hline Lombardy & $-0.76(0.32)$ & & & \\
\hline Lazio & $0.87(0.35)$ & $0.98(0.35)$ & - & $0.9(0.36)$ \\
\hline Sardinia & $2.30(0.58)$ & - & - & - \\
\hline \multicolumn{5}{|l|}{ Purchaser age } \\
\hline $45-54$ & $0.10(0.06)$ & $0.15(0.06)$ & - & - \\
\hline $55-64$ & & $0.20(0.11)$ & - & - \\
\hline$\geq 65$ & $0.16(0.08)$ & - & $0.19(0.09)$ & \\
\hline \multicolumn{5}{|l|}{ Income } \\
\hline Very low & $0.41(0.15)$ & $0.40(0.17)$ & - & \\
\hline Medium & - & - & $0.09(0.05)$ & $0.12(0.05)$ \\
\hline High & $-0.09(0.04)$ & - & - & $0.09(0.04)$ \\
\hline
\end{tabular}

Notes: Significance at the $10 \%$ level, standard errors in brackets.

low-medium sweetness (extra-dry or dry), while the average purchase expense is over three euros. This segment is defined as Prosecco customers. Segment (5) represents $14 \%$ of customers and is the profile of those reporting the highest average purchase expense, more than six euros, for buying brut wines such as Franciacorta, Trento, or Champagne: we refer to this profile as that of Luxury customers of sparkling wines.

We estimate the covariate effects on the initial probabilities through the regression parameters of the multinomial logit model as shown in Equation (2). Table 5 reports the statistically significant coefficients and their corresponding standard errors. The complete results are available from the authors upon request. These effects are estimated on the logit scale, and for instance, the two log-odds referred to an age older than 65 are positive, indicating that customers with such ages tend to be allocated more in segments (3) Sophisticated and (4) Prosecco with respect to (1) Ordinary Sweet. For instance, the odds ratio of older people versus young customers to be in segment (2) is equal to $1.17 \exp (0.16)$.

Living in the South of Italy and earning a low income assign a higher probability to perform purchases in segment (2) Ordinary Brut with respect to segment (1) Ordinary Sweet. Conversely, earning a high income increases the probability of making purchases in segment (5) Luxury with respect to segment (1) and decreases 
the probability of purchasing in segment (2). Customers living in Lombardy tend to be allocated more likely to segment (1) than (2). Purchases of segment (4) Prosecco are more likely to be made by middle-aged consumers (45-54 years old) living in Northeast Italy and the Lazio region and earning a medium-level income. Medium or high-income customers have a higher probability of making purchases in segment (5) Luxury. Also, those living in the Campania and Lazio regions have a high probability of being Luxury customers.

These results show that income affects purchases in an expected direction: customers with higher income are likely to make purchases in the Sophisticated segment. The effect of age and the area where customers live on buying sparkling wines is probably a consequence of different purchase habits and preferences. Family size and life stage have no significant effect on the probability of belonging to certain segments at the beginning of the period.

\section{B. Purchase Dynamics}

The HMM shows the probabilities of switching customers among segments over time, accounting for the covariates' effects. A general understanding of customers' shifts across segments is provided through the average estimated transition matrix.

Figure 1 shows a stylized transition matrix. This is a stochastic matrix that is a squared matrix whose rows sum to one. Rows and columns define five customers' segments, while the vertical and horizontal dimensions represent the probability of transitions from time $t-1$ to time $t$, respectively. The matrix diagonal elements (cells with a gray background) report the probability that customers persist in the same segment over time. High probabilities mean high persistence and imply high customer loyalty, while low probabilities are associated with variety-seeking purchasers, that is, customers who switch from one segment to another. Cells below the main diagonal show the average probability of shifting among the segments in subsequent purchases. Figure 1 shows the interpretation of this stochastic matrix: we assume that row $B_{1}$ (at time $t-1$ ) shows a high value in column $B_{4}$ (at time $t$ ) with respect to the values of column $B_{1}$. This means that customers purchasing $B_{1}$ at time $t-1$ decide to buy $B_{4}$ at time $t$. In other words, $B_{4}$ is highly attractive to customers in $B_{1}$. On the other hand, a high probability in cell $B_{4}-B_{1}$ means that customers in segment $B_{4}$ at time $t-1$ tend to switch to segment $B_{1}$ on the next occasion.

The average estimated transition matrix is reported in Table 6. Customers allocated in segment (1) Ordinary Sweet, (2) Ordinary Brut, and (4) Prosecco are more stable on their preferences than customers in Sophisticated and Luxury segments. We notice that the highest probability outside of the main diagonal is that referred to the transition from Sophisticated to Ordinary Sweet.

The model also investigates how covariates affect these transitions probabilities. Specifically, knowing how switching across brands is affected by geographical, demographic, or economic factors is extremely helpful in building ad hoc strategies 
Figure 1

The Transition Matrix: Illustration with Five Customer Segments

\begin{tabular}{|c|c|c|c|c|c|}
\hline Time $_{t-1}$ Time $_{t}$ & $B_{1}$ & $B_{2}$ & $B_{3}$ & $B_{4}$ & $B_{5}$ \\
\hline$B_{1}$ & -. & \multicolumn{2}{|c|}{ Switch } & 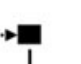 & \\
\hline$B_{2}$ & \multirow{2}{*}{\multicolumn{2}{|c|}{ Attractiveness }} & & \multirow{2}{*}{\multicolumn{2}{|c|}{ Attractiveness }} \\
\hline$B_{3}$ & & & & & \\
\hline$B_{4}$ & & & & $\forall$ & \\
\hline$B_{5}$ & & & & & \\
\hline
\end{tabular}

Notes: Matrix main diagonal: loyalty (high numbers), variety-seeking (low numbers). Change brand (horizonal movements). Brand/segment attractiveness (vertical movements).

Table 6

Estimated Average Transition Matrix from the HMM

\begin{tabular}{lccccc}
\hline Time t-1 & $\begin{array}{c}(1) \\
\text { Ordinary } \\
\text { Sweet }\end{array}$ & $\begin{array}{c}(2) \\
\text { Ordinary } \\
\text { Brut }\end{array}$ & $\begin{array}{c}(3) \\
\text { Sophisticated }\end{array}$ & $\begin{array}{c}\text { (4) } \\
\text { Prosecco }\end{array}$ & \begin{tabular}{c} 
Luxury \\
\hline Ordinary sweet (1)
\end{tabular} \\
Ordinary brut (2) & $\mathbf{0 . 6 6}$ & $\mathbf{0 . 1 2}$ & 0.09 & 0.09 & 0.04 \\
Sophisticated (3) & 0.06 & $\mathbf{0 . 7 4}$ & 0.04 & $\mathbf{0 . 1 1}$ & 0.04 \\
Prosecco (4) & 0.18 & $\mathbf{0 . 1 4}$ & $\mathbf{0 . 5 2}$ & $\mathbf{0 . 1 1}$ & 0.05 \\
Luxury (5) & $\mathbf{0 . 1 1}$ & $\mathbf{0 . 1 2}$ & 0.04 & $\mathbf{0 . 7 2}$ & 0.05 \\
\hline
\end{tabular}

Notes: gray background persistence in the same state; bold, probabilities greater than 0.1 .

for targeting these markets. In the following, we will keep the exposition simple. Instead of reporting the estimated regression coefficients as in Equation (3), we show the average estimated transition matrices across some relevant categories of the covariates. Tables 7 and 8 show the matrices referred to the area of residence, income, and family life stages. Other comparisons are possible, but they are not reported for the economy of the article. Table 7 reports the transition matrices of customers living in Apulia (Southern Italy) and Lombardy (Northern Italy). In Apulia, we observe a better loyalty to ordinary sparkling wines (Ordinary Sweet and Brut) and variety-seeking purchases in the Sophisticated, Luxury, and Prosecco segments. For instance, consumers of Prosecco in Apulia have a high probability of buying 
Ordinary Brut at the next purchase. Instead, in Lombardy, we see a greater loyalty, except for ordinary brut wines, while VSB is observed in purchasers switching from Ordinary Brut, Sophisticated, Prosecco, and Luxury segments to the Ordinary Sweet one. Customers in the Luxury segment are the most unstable, confirming that purchases in this segment are strongly occasional. The different behavior in purchasing sparkling wines in northern vs. southern Italian regions may be a consequence of several factors such as habit or living close to the production areas (located mostly in northern regions such as Lombardy).

Table 8 compares purchasing behavior over time across different incomes and family life stages, reporting the estimated average transition matrices of three income levels in the class of age 45-54 (left side) and three different life stages (right side).

Looking at the estimated matrices referred to the income level reported in Table 8, we observe a greater loyalty of the Sophisticated segment. Low-income customers (upper left table) switch mainly between Prosecco and Ordinary (brut and sweet) sparkling wines. This purchasing behavior is also found in higher-income families, suggesting that income mainly affects purchases of high-priced sparkling wines. Indeed, these customers show the highest probabilities of transition from Ordinary Brut to the Sophisticated, Prosecco, and Luxury segments.

The right sub-tables in Table 8 report the estimated transition probabilities referred to pre-families (singles or couples with no children), established families (couples with teenage children), and post-families (singles or couples with no children under 18). Going from pre- to post-families, loyalty to Sophisticated and Prosecco purchases increases. In pre-families, Prosecco and Sophisticated purchasers shift mainly to the Ordinary Brut and Ordinary Sweet segments; in established and post-families, this behavior is still existing but is less pronounced. Interestingly, pre-families show the highest probabilities to transit from the Ordinary Sweet, Sophisticated, and Prosecco segments to other segments with respect to their counterparts.

The analyses restricted to Italian regions, income, and family life stages report an important effect on loyalty and VSB; the latter is detected in the area of residence and is likely associated with different consumption habits. Income and life stage contribute positively to purchase high-priced sparkling wines.

\section{Discussion and Conclusions}

The paper analyzes the dynamics of sparkling wine purchases over two years through a multivariate HMM, accounting for the sparsity of the purchases. The results point out homogenous latent profiles corresponding to groups of consumers sharing similar preferences in repeated sparkling wine purchases. The influence of the socio-economic characteristics, such as area of residence, age, income, family size, 
Table 7

Estimated Average Transition Matrix in Apulia and Lombardy

\begin{tabular}{|c|c|c|c|c|c|c|c|c|c|c|}
\hline & \multicolumn{5}{|c|}{ Apulia } & \multicolumn{5}{|c|}{ Lombardy } \\
\hline & $\begin{array}{c}\text { Ordinary } \\
\text { Sweet }\end{array}$ & $\begin{array}{c}\text { Ordinary } \\
\text { Brut }\end{array}$ & Sophisticated & Prosecco & Luxury & $\begin{array}{c}\text { Ordinary } \\
\text { Sweet }\end{array}$ & $\begin{array}{c}\text { Ordinary } \\
\text { Brut }\end{array}$ & Sophisticated & Prosecco & Luxury \\
\hline Ordinary sweet & 0.67 & 0.12 & 0.08 & 0.07 & 0.06 & 0.78 & 0.04 & 0.10 & 0.03 & 0.05 \\
\hline Ordinary brut & 0.09 & 0.78 & 0.03 & 0.07 & 0.03 & 0.17 & 0.60 & 0.09 & 0.12 & 0.02 \\
\hline Sophisticated & 0.07 & 0.16 & 0.71 & 0.06 & 0.00 & 0.18 & 0.05 & 0.69 & 0.03 & 0.05 \\
\hline Prosecco & 0.06 & 0.25 & 0.12 & 0.56 & 0.02 & 0.13 & 0.12 & 0.10 & 0.61 & 0.04 \\
\hline Luxury & 0.19 & 0.26 & 0.05 & 0.18 & 0.33 & 0.24 & 0.07 & 0.13 & 0.05 & 0.51 \\
\hline
\end{tabular}

Notes: gray background persistence in the same state; bold, probabilities greater than 0.1 . 
Table 8

Estimated Transition Matrix in for Income and Life-Stage Comparison

\begin{tabular}{|c|c|c|c|c|c|c|c|c|c|c|}
\hline & \multicolumn{5}{|c|}{ Low-Income Customers Aged 45-54 } & \multicolumn{5}{|c|}{ Pre-Family } \\
\hline & Ordinary Sweet & Ordinary Brut & Sophisticated & Prosecco & Luxury & Ordinary Sweet & OrdinaryBrut & Sophisticated & Prosecco & Luxury \\
\hline Ordinary sweet & 0.76 & 0.04 & 0.10 & 0.07 & 0.03 & 0.53 & 0.15 & 0.15 & 0.10 & 0.07 \\
\hline Ordinary brut & 0.08 & 0.73 & 0.08 & 0.08 & 0.03 & 0.07 & 0.70 & 0.11 & 0.09 & 0.02 \\
\hline Sophisticated & 0.09 & 0.11 & 0.72 & 0.05 & 0.02 & 0.28 & 0.14 & 0.50 & 0.05 & 0.02 \\
\hline Prosecco & 0.14 & 0.26 & 0.08 & 0.49 & 0.02 & 0.10 & 0.36 & 0.12 & 0.38 & 0.05 \\
\hline \multirow[t]{3}{*}{ Luxury } & 0.22 & 0.19 & 0.07 & 0.12 & 0.40 & 0.12 & 0.15 & 0.17 & 0.03 & 0.52 \\
\hline & \multicolumn{5}{|c|}{ Medium-Income Customers Aged 45-54 } & \multicolumn{5}{|c|}{ Established Family } \\
\hline & Ordinary Sweet & Ordinary Brut & Sophisticated & Prosecco & Luxury & Ordinary Sweet & OrdinaryBrut & Sophisticated & Prosecco & Luxury \\
\hline Ordinary sweet & 0.79 & 0.02 & 0.12 & 0.03 & 0.04 & 0.74 & 0.05 & 0.12 & 0.02 & 0.07 \\
\hline Ordinary brut & 0.11 & 0.61 & 0.11 & 0.10 & 0.06 & 0.14 & 0.57 & 0.17 & 0.08 & 0.04 \\
\hline Sophisticated & 0.09 & 0.05 & 0.76 & 0.04 & 0.05 & 0.09 & 0.09 & 0.75 & 0.03 & 0.03 \\
\hline Prosecco & 0.15 & 0.19 & 0.17 & 0.44 & 0.05 & 0.14 & 0.19 & 0.13 & 0.47 & 0.06 \\
\hline \multirow[t]{3}{*}{ Luxury } & 0.19 & 0.10 & 0.17 & 0.08 & 0.46 & 0.17 & 0.10 & 0.20 & 0.09 & 0.43 \\
\hline & \multicolumn{5}{|c|}{ High-Income Customers Aged 45-54 } & \multicolumn{5}{|c|}{ Post-Family } \\
\hline & Ordinary Sweet & Ordinary Brut & Sophisticated & Prosecco & Luxury & Ordinary Sweet & OrdinaryBrut & Sophisticated & Prosecco & Luxury \\
\hline Ordinary sweet & 0.77 & 0.01 & 0.12 & 0.02 & 0.08 & 0.75 & 0.04 & 0.12 & 0.04 & 0.05 \\
\hline Ordinary brut & 0.10 & 0.55 & 0.13 & 0.11 & 0.10 & 0.10 & 0.67 & 0.08 & 0.10 & 0.06 \\
\hline Sophisticated & 0.11 & 0.03 & 0.79 & 0.03 & 0.05 & 0.11 & 0.07 & 0.72 & 0.05 & 0.05 \\
\hline Prosecco & 0.16 & 0.15 & 0.12 & 0.52 & 0.05 & 0.16 & 0.20 & 0.11 & 0.49 & 0.04 \\
\hline Luxury & 0.20 & 0.04 & 0.14 & 0.08 & 0.54 & 0.18 & 0.12 & 0.15 & 0.09 & 0.46 \\
\hline
\end{tabular}

Notes: gray background persistence in the same state; bold, probabilities greater than 0.1 . 
and family life stage, is assessed through estimated parameters on the initial and transition probabilities of the latent Markov chain.

The estimated parameters show significant effects of age, income, type of family, and area of residence. Older and high-income purchasers show loyalty to better quality sparkling wines, while young purchasers (young families) are more variety seekers. These results are in contrast with Bruwer and Li (2007), who reported a high propensity to experiment with new wines in older consumers, while they are in line with Fountain and Lamb (2011) and Olsen et al. (2015), who showed that Millennials prefer different varietals. Regional segmentation reports differences in loyalty and in variety seekers. The residence area is likely to be associated with wine familiarity or knowledge, higher in northern Italian Regions, such as Veneto or Lombardy. Similarly, to Dodd, Pinkleton, and Gustafson (1996), the consumer purchases known brands to avoid searching for information or to lower the risk of making a wrong choice. Price has a strong effect on sparkling wine purchases, especially in high price positioned ones (Luxury and Sophisticated segments), while it produces variety-seeking tendencies, as also pointed out by some authors (Hussain, Cholette, and Castaldi, 2007). The results concerning the appellation are in line with those presented in Rossetto and Gastaldello (2018) for Prosecco and no appellation such as Ordinary Sweet or Brut groups; however, the HMM shows a lower market share of Prosecco segments and a higher VSB in its customers.

Compared to the existing models employed in the literature, such as loyalty and VSB, the proposed methodology based on the HMM works differently. For instance, Adamowicz and Swait (2012) applied utility-maximizing on scanner data producing a market segmentation with respect to habits and VSB on two food products. Seetharaman (2004) used a random utility model on scanner data to measure the sources of dependence. Recently, Wang and Liu (2020) adopted a random effect model on yogurt and soft drinks scanner data to investigate the effect of socio-economic covariates on the heterogeneous state of dependence. Ellis and Thompson (2018) evaluated the VSB in the wine market through the Van Trijp and Steenkamp scale (1992), while Olsen et al. (2015) adopted the Schwartz Value Inventory and the VARSEEK scale. The proposed HMM is based on latent variables having a discrete distribution, and it allows us great flexibility to model complex dependence structures such as those arising in wine or food markets having a wide assortment of sensory and hedonic attributes (e.g., cheeses). It permits to perform model-based clustering, identifying individuals with similar patterns of changes, allowing them to move between clusters across time.

The results provide strategic and managerial insights. First, the market is roughly divided into two main groups: consumers who repeat the purchase of low-priced sparkling wines (sweet or brut, having no appellation) and consumers who regularly buy Prosecco. Second, the loyalty is higher for Prosecco and Ordinary Brut than for Ordinary Sweet and high-priced sparkling wines. This result is associated with consumption occasions, usually higher for brut and Prosecco than for sweet and expensive wines, mostly consumed during celebrations or special events. Third, the 
transitions among states reveal the VSB of purchasers. Looking at Prosecco and ordinary brut consumers, we observe that Prosecco attracts people living in Veneto (they shift from Ordinary Brut to Prosecco), young consumers (less than 34 years of age), families with two or three components, and older families. On the other hand, consumers living in Sicily or Sardinia, between 45 and 64 years of age, with medium income after a certain period may leave the Prosecco group. Going to regional, income, and family life stage comparisons, we see a higher loyalty for Ordinary Sweet sparkling wines, and in the Sophisticated group, while living in northern regions, earning a low or high income, the age and family life stage may change the VSB of some purchasers. While income, and especially a low one, leads the consumer to be attracted by discounting strategies, the area of residence may influence the habits of consumers.

Implications for producers and sellers are referred to as loyalty and VSB and covariates effects. For instance, Prosecco consumers show an overall high loyalty due to heterogeneous purchase behaviors, which are pointed out by the HMM model used. Segmentation and purchasing results are useful for retailers to refine discount and assortment policies throughout the year. This analysis can be extended to food markets where items are frequently purchased throughout the year and show a wide assortment (sensory, hedonic attributes). When data becomes available, the HMM could evaluate consumers' purchase patterns in switching among sensory attributes (e.g., flavors) and non-sensory ones (e.g., brand, price).

Data analysis was done at the category level (price range, type of wine, appellations), but the state of dependence among winery brands was not investigated. Also, the available panel data do not provide information on the wine knowledge of the purchasers or the customers' values or attitudes, which are essential predictors in purchasing wine (Ellis and Thompson, 2018). Furthermore, this analysis catches the sparkling wine purchase behavior in the large retail channel while excluding specialized wine shops and online channels. Thus, the paper does not evaluate high price market segments having a different brand assortment and price positioning.

Further research can be done on a sample that includes both sparkling and still wines. Sparkling is usually considered a different category; however, analysis on overall wine purchases may shed light on the associations among different types of wine while showing the wine portfolio of consumers. The analytical tool of HMMs may contribute to discovering relevant aspects of the consumer dynamics when applied with data obtained in other markets or from other marketing channels such as online sales.

\section{References}

Adamowicz, W. L., and Swait, J. D. (2012). Are food choices really habitual? Integrating habits, variety-seeking and compensatory choice in a utility-maximizing framework. American Journal of Agricultural Economics, 95(1), 17-41. 
Bacci, S., Pandolfi, S., and Pennoni, F. (2014). A comparison of some criteria for states selection in the latent Markov model for longitudinal categorical data. Advances in Data Analysis and Classification, 8, 125-145.

Baltas, G., Kokkinaki, F., and Loukopoulou, A. (2017). Does variety seeking vary between hedonic and utilitarian products? The role of attribute type. Journal of Consumer Behaviour, 16(6), 1-12.

Barharrell, B., and Denison, T. J. (1995). Involvement in a routine food shopping context. British Food Journal, 97(4), 24-29.

Bartolucci, F., Farcomeni, A., and Pennoni, F. (2013). Latent Markov Models for Longitudinal Data. Boca Raton: Chapman \& Hall/CRC.

Bartolucci, F., Farcomeni, A., and Pennoni, F. (2014). Latent Markov models: A review of a general framework for the analysis of longitudinal data with covariates (with discussion). Test, 23, 433-465.

Bartolucci, F., Pandolfi, S., and Pennoni, F. (2017). LMest: An R package for latent Markov models for longitudinal data. Journal of Statistical Software, 81(4), 1-38.

Bassi, F., Pennoni, F., and Rossetto, L. (2020). The Italian market of sparkling wines: Latent variable models for brand positioning, customer loyalty, and transitions across brands' preferences. Agribusiness, 31(4), 542-567.

Bruwer, J., and Li, E. (2007). Wine-related lifestyles, (WRL) market segmentation: Demographic and behavioral factors. Journal of Wine Research, 18(1), 19-34.

Campbell, M. C., and Goodstein, R. C. (2001). The moderating effect of perceived risk on consumers' evaluations of product incongruity: Preference for the norm. Journal of Consumer Research, 28(3), 439-449.

Charters, S., Velikova, N., Ritchie, C., Thach, L., Dodd, T. H., Fish, N., Herbst, F., and Terblanche, N. (2011). Generation Y and sparkling wines: A cross-cultural perspective. International Journal of Wine Business Research, 23(2), 161-175.

Clogg, C. C., and Goodman, L. A. (1984). Latent structure analysis of a set of multidimensional contingency tables. Journal of the American Statistical Association, 79(388), $762-771$.

Culbert, J. A., Ristic, R., Ovington, A., Saliba, A. J., and Wilkinson, K. (2017). Influence of production method on the sensory profile and consumer acceptance of Australian sparkling white wine styles. Australian Journal of Grape and Wine Research, 23(2), 170-178.

Dempster, A. P., Laird, N. M., and Rubin, D. B. (1977). Maximum likelihood from incomplete data via the EM algorithm (with discussion). Journal of the Royal Statistical Society B, 39 (1), 1-38.

Diehl, K., and Poynor, C. (2010). Great expectations?! Assortment size, expectations, and satisfaction. Journal of Marketing Research, 47(2), 312-322.

Dodd, T. H., Pinkleton, B. E., and Gustafson, A. W. (1996). External information sources of product enthusiasts: Differences between variety seekers, variety neutrals, and variety avoiders. Psychology and Marketing, 13(3), 391-304.

Ellis, D., and Caruana, A. (2018). Consumer wine knowledge: Components and segments. International Journal of Wine Business Research, 30(3), 277-291.

Ellis, D., and Thompson, F. M. (2018). The effect of wine knowledge type on variety seeking behavior in wine purchasing. Journal of Wine Research, 29(2), 71-86.

Fountain, J., and Lamb, C. (2011). Generation Y as young wine consumers in New Zealand: How do they differ from Generation X? International Journal of Wine Business Research, 23(2), 107-124.

Gustavsen, G. W., and Rickertsen, K. (2019). Personality traits and consumption of wine and beer. Journal of Wine Economics, 14(4), 392-399. 
Hart, J., and Alston, J. M. (2020). Assessing consumption patterns in the U.S. alcohol market: Disaggregated spatial analysis. Journal of Wine Economics, 15(1), 5-41.

Hussain, M., Cholette, S., and Castaldi, R. (2007). Determinants of wine consumption of US consumers: An economic analysis. International Journal of Wine Business Research, 19(1), $49-62$.

Inman, J. J. (2001). The role of sensory-specific satiety in attribute-level variety seeking. Journal of Consumer Research, 28(1), 105-120.

Kelley, K., Zelinskie, J., Centinari, M., Gardner, D., Govindasamy, R., Hyde, J., Rickard, B., and Storchmann, K. (2017). Consumer preferences for sustainable wine attributes: A conjoint analysis. Journal of Wine Economics, 12(4), 416-425.

Knox, S., and Walker, D. (2001). Measuring and managing brand loyalty. Journal of Strategic Marketing, 9(2), 111-128.

Madureira, T. C. F. F, and Simoes de Sousa Nunes, F. J. (2013). Relevant attributes of Portuguese wines: Matching regions and consumer's involvement level. International Journal of Wine Business Research, 25(1), 75-86.

McAlister, L. (1982). A dynamic attribute satiation model of variety seeking behavior. Journal of Consumer Research, 9(2), 141-150.

Meixner, O., and Knoll, W. (2012). An expanded model of variety-seeking behaviour in food product choices. British Food Journal, 114(11), 1571-1586.

Mueller, S., Remaud, H., and Chabin, Y. (2011). How strong and generalizable is the Generation Y effect? A cross-cultural study for wine. International Journal of Wine Business Research, 23(2), 125-144.

Nielsen (2017). Homescan consumer panel data on sparkling wine purchases. Assago, Milano, Italy: Nielsen Company Italia.

Olsen, J. E., Atkin, T., Thach, L., and Cuellar, S. S. (2015). Variety seeking by wine consumers in the southern states of the US. International Journal of Wine Business Research, 27(4), 260-280.

Onofri, L., Boatto, V., and Dal Bianco, A. (2015). Who likes it "sparkling"? An empirical analysis of Prosecco consumers' profile. Agricultural and Food Economics, 3(11), 1-15.

Pennoni, F. (2014). Issues on the Estimation of Latent Variable and Latent Class Models. Saarbücken: Scholars Press.

Raju, P. S. (1980). Optimum stimulation level: Its relationship to personality, demographics, and exploratory behavior. Journal of Consumer Research, 7(3), 272-282.

Rossetto, L., and Gastaldello, G. (2018). The loyalty structure of sparkling wine brands in Italy. Journal of Wine Economics, 13(4), 409-418.

Rungie, C., Laurent, G., Mtimet, N., and Jarvis, W. (2006). Revealed preference attribute modelling using repeated purchases. Marketing Bulletin, 17, 1-6.

Seetharaman, P. B. (2004). Modeling multiple sources of state dependence in random utility models: A distributed lag approach. Marketing Science, 23(2), 263-271.

Sevilla, J., Lu, J., and Kahn, B. E. (2019). Variety seeking, satiation, and maximizing enjoyment over time. Journal of Consumer Psychology, 29(1), 89-103.

Thach, L., and Olsen, J. (2006). Market segment analysis to target young adult wine drinkers. Agribusiness: An International Journal, 22(3), 307-322.

Thiene, M., Scarpa, R., Galletto, L., and Boatto, V. (2013). Sparkling wine choice from supermarket shelves: The impact of certification of origin and production practices. Agricultural Economics, 44(4-5), 523-536.

Thomadsen, R., and Seetharaman, P. B. (2018). The strategic effects of state-dependent consumer preferences: The roles of habits and variety seeking. In B. Verplanken (ed.), The Psychology of Habit, 131-150. Cham, Switzerland: Springer. 
Van Trijp, H. C. M., Hoyer, W. D., and Inman, J. (1996). Why switch? Product category-level explanations for true variety-seeking behavior. Journal of Marketing Research, 33(3), 281-292.

Van Trijp, H., and Steenkamp, J. B. (1992). Consumers' variety seeking tendency with respect to foods: Measurement and managerial implications. European Review of Agricultural Economics, 19(2), 181-195.

Vecchio, R., Lisanti, M. T., Caracciolo, F., Cembalo, L., Gambuti, A., Moio, L., Siani, T., Marotta, G., Nazzaro, C., and Piombino, P. (2018). The role of production process and information on quality expectations and perceptions of sparkling wines. Journal of the Science of Food and Agriculture, 99(1), 124-135.

Venkatesan, M. (1973). Cognitive consistency and novelty seeking. In S. Ward and T. S. Robinson (eds.), Consumer Behavior: Theoretical Sources, 353-384. Englewood Cliffs, NJ: Prentice Hall.

Verdonk, N., Wilkinson, J., Culbert, J., Ristic, R., Pearce, K., and Wilkinson, K. (2017). Toward a model of sparkling wine purchasing preferences. International Journal of Wine Business Research, 29(1), 58-73.

Corriere Vinicolo (2019). Il Vino in Cifre 2019. Corriere Vinicolo, 1, 72.

Viot, C. (2012). Subjective knowledge, product attributes, and consideration set: A wine application. International Journal of Wine Business Research, 24(3), 219-248.

Wang, X., and Liu, Y. (2020). Explaining Consumer Heterogeneity in Structural StateDependence. Sustainability, 12(7), 2597.

Yoon, S., and Kim, H. C. (2018). Feeling economically stuck: The effect of perceived economic mobility and socioeconomic status on variety seeking. Journal of Consumer Research, 44(5), 1141-1156. 